\title{
Hubert Igliński
}

Faculty of International Business and Economics, Poznań University of Economics and Business, Poland

\section{ECONOMIC EFFECTS OF ROAD TRANSPORT AUTONOMIZATION}

\begin{abstract}
Work on fulfilling the dream of self-guiding vehicles began almost 100 years ago. Thanks to the significant progress that has been made in recent years, it can finally be assumed that fully autonomous road vehicles will most likely appear in 10-15 years. It will be necessary to wait much longer for their proliferation, but their economic and social potential is huge. Therefore, the aim of the paper's author is to make a preliminary and for formal reasons also a synthetic review of the economic effects of the road transport autonomization.
\end{abstract}

Keywords: autonomous vehicles, road transport, external costs of transport

\section{Introduction}

In the 1890s, when the first automobile appeared, many people saw in them a miracle cure for all problems of contemporary transport, especially in cities. It seemed that finally serious and expensive problems would disappear, first of all supplying horses with fodder, the need to build and maintain a stable for them, huge amounts of dung found in the streets and sidewalks, and widespread stench. In addition, horse transport was slow and the level of congestion in cities was high.

In fact, all the above problems were solved in a short time, but with the proliferation of cars, new, even more serious and some of the old problems appeared, e.g. congestion returned, only on a much larger scale. Today, once again in history, a huge change in transport is taking place. The model of mobility, widely used in developed countries, is changing, especially the concept of a car and its perception, which is subject to thorough redefinition. The current paradigm of the car as a private and internal combustion means of human-driven transport is heading towards a shared, electric and autonomous vehicle. The vehicle is deprived 
of the whole sociological and psychological meaning, i.e. emphasizing the material status of the car owner, or his masculinity, and sometimes also ideology or political preferences (e.g. preferred by Democrats Toyota Prius or Tesla, vs. a republican pick-up e.g. Ford F150 or Dodge RAM).

\section{The genesis of autonomous cars and basic concepts}

The dream of building autonomous vehicles (AV), i.e. self-guiding vehicles without a driver, appeared already in the 1920s. One of the key reasons for this was the concern for improving traffic safety and reducing the number of fatalities. Today it seems unimaginable, but in the years 1919-1923 in the USA, when the level of motorization even in 1923 did not exceed 120 cars per 1000 inhabitants ${ }^{1}$, in road accidents over 60000 people died (and in the entire decade of the 1920s, over 200 000), which is more than American soldiers in all the battles of the First World War'.

The first vehicle without a driver was demonstrated on August $5^{\text {th }}, 1921$ at the air base in Dayton, Ohio. At the same time, it was not a de facto autonomous vehicle but only a remote controlled one. Initially, the control signal was sent via a cable from a car following the vehicle without a driver and later by radio waves. In the following decades, numerous concepts and designs of self-driving cars appeared, new improvements were introduced, such as the now widely known cruise control system - implemented by Chrysler in 1958 and called the "autopilot" ${ }^{3}$. Significant acceleration of works took place from the end of the 1970s, especially in Japan and Germany thanks to Ernst Dickmanns, and then in the USA mainly through Grand Challenge organized by DARPA (Defense Advanced Research Project Agency). It was also influenced by the rapid development and increasingly widespread use of electronic circuits in control systems.

The Society of Automotive Engineers divides vehicles into 6 levels of autonomy. Level 0 are the simplest vehicles in which the driver is not supported by any systems that facilitate driving. On the next four levels from 1 to 4 , the role of the driver decreases and finally level 5 means full autonomy. Driving a vehicle on level 5 takes place without the need for any driver interference, thus it is possible to eliminate the steering wheel, pedals, mirrors, etc.

There are currently vehicles that are representing the second level of autonomy. They can park themselves (parallel and perpendicular), stay on a given traffic lane, adjust the speed themselves (e.g. by reading signs of acceptable speed), accelerate and brake, keeping a safe distance from the vehicle ahead etc. Level 3 begins to be available in the most luxury and, at the same time, expensive vehicles, such

\footnotetext{
https://www.fhwa.dot.gov/ohim/summary95/mv200.pdf (access: 9.03.2018).

P.D. Norton, Fighting Traffic. The Dawn of the Motor Age in the American City, The MIT Press, Cambridge 2008, p. 21-22.

3 F. Kröger, Automated Driving in Its Social, Historical and Cultural Context [in:] Autonomous Driving. Technical, Legal and Social Aspects, eds. M. Maurer, J.Ch. Gerdes, B. Lenz, H. Winner, Springer Verlag, Berlin 2016, p. 42-56.
} 
as the Audi A8 available from 20194. The car is being driven alone, but the driver must still be on the alert and take over when the system requires it.

Some of the companies claim that levels 2 and 3 are not very secure, because although these cases are rarer, due to the continuous learning of vehicles and their programmers, the vehicle may require driver intervention. It is highly probable that such a reaction will be late, especially when the attention of the driver is focused on reading the newspaper or tracking content on the smartphone and also inferior quality, in which case the driver must drive the vehicle all the time ${ }^{5}$. That is why producers like Waymo and Uber are trying to reach level 4 immediately, i.e. full autonomy in a specific city environment or at the beginning of its part. The exact delimitation of the area of functioning of vehicles on level 4 and on the shared addition allows to better calibrate all vehicle sensors (including lidar) so as to take into account the specific weather conditions of the area and its topography and other characteristics, e.g. a large number of freely moving animals.

The progress in the process of road transport autonomy, which has taken place in recent years, is enormous. Of course, there are still many technical, organizational, legal and mental barriers to overcome, such as the perception of AV by users as uncertain and dangerous ${ }^{6}$. Users will also have to get used to their new exterior appearance as well as the interior of vehicles, because the form and shapes of AV will follow the features they offer. However, the current pace of progress is so great that it can be assumed that fully autonomous cars will appear no more than 10-15 years. According to specialists from IHS Automotive, it will be around 2030. At the same time, they estimate that in the entire world in 2035 the number of autonomous vehicles in operation will be nearly 55 million $^{7}$. This is a small number compared to the total number of road vehicles currently traveling around the world (over 1 billion), however, it should be remembered that most of these vehicles will be shared, and therefore will replace up to 0.5 billion modern private cars and thus will radically change the known us a road transport system ${ }^{8}$.

\section{Economic effects}

Autonomous vehicles move in a harmonic way and at much smaller intervals between them, therefore they make much better use of the available capacity of existing infrastructure than human drivers. It is also assumed that the majority

4 Ch. Paukert, Audi says 2019 A8's Level 3 self-driving tech capable of doubling speed, https://www.cnet. com/roadshow/news/audi-says-2019-a8-level-3-self-driving-tech-capable-of-doubling-speed/ (access: 9.03.2018).

5 C. Thompson, New details about the fatal Tesla Autopilot crash reveal the driver's last minutes, http://www. businessinsider.com/details-about-the-fatal-tesla-autopilot-accident-released-2017-6? IR =T (access: 9.03.2018).

6 Without comparison PAs are better seen in cities, e.g. in Phoenix or Pittsburgh, where they are already operated in normal traffic and where passengers can already use them.

$7 \mathrm{http}: / /$ press.ihs.com/press-release/automotive/self-driving-cars-moving-industrys-drivers-seat (access: 9.03.2018).

8 J.B. Greenblatt, S. Shaheen, Automated Vehicles, On-Demand Mobility, and Environmental Impacts, Current Sustainable/Renewable Energy Reports 2015, 2, p. 74-81. 
of these vehicles will be shared (car sharing and ridesharing), which will additionally reduce the level of transport congestion by reducing the number of cars in motion? The "parking cruising" phenomenon, which is usually slow moving in search of a free parking space, which significantly increases the level of congestion, will also decrease. This will happen because the $\mathrm{AV}$ can be left anywhere in the immediate vicinity of the destination, and the vehicle will park or go for more travelers.

However, if the use of them will be so easy (according to VW, one tiny device and one click is enough) and pleasant, and in addition cheap ${ }^{10}$ will certainly have a "rebound effect" and will stimulate new demand for travel, as well as attract some passengers from public transport. Thus, the combined demand will increase significantly and the level of congestion may increase even more, covering a significant part of the day, and not just periods of communication peaks, especially if the AVs become avaible enough to most users as private cars. Therefore, the replacement of modern cars with autonomous vehicles will have to be subject to precise regulations and will require the creation of new, much more extensive and flexible payment systems taking into account numerous parameters in order to prevent the occurrence of excessive congestion.

The mutual relations between public transport and autonomous vehicles remain unknown. Studies carried out so far show that the high availability of services provided by Uber, Lyft and similar operators who invest heavily in the autonomy (the so-called robo taxi) caused the outflow of some public transport passengers ${ }^{11}$. In the light of these observations, it is reasonable for operators or managers of municipal public transport systems to start offering services of flexible and autonomous public transport carried out by autonomous vehicles. So as not to lead to devastating competition, but enrich and complement the current offer. Small AVs could successfully serve residents of suburbs, delivering them to stops and stations of much more efficient and fast traditional means of transport - railways, subways, trams etc. As well as between the suburbs and wherever due to tight development or other restrictions of entry typical public transport vehicles is currently ineffective or even impossible.

The influence of AV on spatial planning is also a mystery. A typical private passenger car is used on average for only $5 \%$ of the time and the remaining nearly 23 hours is parked. This forces the need to create a significant number of parking spaces. Research carried out in American cities indicates that every registered car has an average of 6 times more parking space than it occupies (in Europe from 4 to 5), which means that in developed countries with a high level of motorization public car parks occupy an average of $15 \%$ of the surface cities and in their centers about $1 / 3^{12}$. The dissemination of $\mathrm{AV}$, especially if they are shared, will make that their usage level will be many times higher than currently owned cars and thanks to this

9 D. Shoup, Cruising for Parking, Access 2007, 30, p. 16-22.

10 The use of shared autonomous vehicles will certainly be significantly cheaper than with modern taxis, because $40 \%$ of the total travel costs are drivers' costs. That is why companies such as Uber invest so intensively in the development of autonomy.

11 R.R. Clewlow, G.S. Mishra, Disruptive Transportation: The Adoption, Utilization and Impacts of Ride-Hailing in the United States, Institute of Transportation Studies, University of California, Davis 2017, p. 24-26.

12 E. Ben-Joseph, ReThinking a Lot. The Design and Culture of Parking, The MIT Press, Cambridge 2012, p. 7. 
will allow to recover a significant part of the parking space. It can be used for e.g. housing, trade or services, but also to create parks and places for recreation and rest, which is likely to attract residents closer to the center. In addition, cities will save gigantic financial resources, because the construction of further parking spaces in the centers will cease to be necessary, especially the most expensive ones within multi-level car parks ${ }^{13}$. New parking lots for AV will be fully automatic without access for people, ramps, staircases, lifts etc., which will take up much less space and will be cheaper.

On the other hand, there is a danger that if the time spent in an autonomous car will never be lost again (you will be able to read, sleep, play, watch movies etc.), it will not be as strong as today's motivation to live closer to the center and limit distance traveled every day. As a result, the city will spread even more and an extremely large hybrid urban-rural settlement structure will be created. Such a scenario will lead to the appropriation of huge tracts of agricultural and green areas by housing and road infrastructure, which will entail enormous expenses for the construction and maintenance of this infrastructure and will also increase energy consumption longer and more frequent trips. Therefore, again a lot depends on proper spatial planning and quality of buildings and services offered, as well as travel costs for autonomous vehicles.

Autonomous vehicles, regardless of the drive, give the possibility of a significant, at least a few dozen percent, reduction in energy consumption and thus the emission of greenhouse gases and other pollutants emitted by cars. This may be due to their ability to travel in convoys and thus significantly reduce aerodynamic drag. In addition, the need to develop high maximum speeds, high power and fast acceleration will disappear, because AV will not break any regulations (especially speed limits) and because especially shared AV will be stripped of the entire social and psychological context of current cars. This will reduce their mass (small, light engines, possibly smaller batteries) and thus the energy needs for their acceleration and maintaining speed ${ }^{14}$. The aforementioned reduction of the congestion level will also have a very positive effect on the reduction of energy consumption. According to the author's research, fuel consumption is in Poznan in the morning rush hours by as much as $50 \%$ higher than in optimal conditions ${ }^{15}$. Also on the out-of-town routes, a $25 \%$ reduction in energy consumption can be expected, as long as the level of autonomous vehicles in traffic reaches $90 \%{ }^{16}$. As a result, the reduction of pollutant emissions will improve the condition of the natural environment and human health and the attractiveness of life in the city will increase, and at the same time it will be possible to reduce expenditure on healthcare in this area. A decrease in greenhouse gas emissions will reduce the risk of catastrophic climate change,

13 It turns out that in Poznań even a single-level P\&R car park can be extremely expensive. A newly built car park on the estate Sobieski cost about PLN 38.000 for a parking place.

14 H. Igliński, M. Babiak, Analysis of the Potential of Autonomous Vehicles in Reducing the Emissions of Greenhouse Gases in Road Transport, Procedia Engineering 2017, 192, p. 353-358.

15 H. Igliński, Kongestia transportowa w Poznaniu $i$ wybrane sposoby jej ograniczenia, Transport Miejski i Regionalny 2009, 3, p. 1-8.

16 Preparing a Nation for Autonomous Vehicles: Opportunities, Barriers and Policy Recommendations, ENO Center for Transportation, 2013, p. 8-10. 
unless of course the rebound effect (Jevons paradox) does not occur as a result of the drop in travel costs, and people will not start riding more.

Annually, around 1.25 million people die in road accidents in the world and up to 50 million are injured ${ }^{17}$. Most of them suffer from accidents in developing countries, and the proliferation of AV in these countries will have to wait a long time. However, this does not change the fact that autonomous vehicles are nowadays much safer. Unlike modern human drivers, AV will never break the rules, especially speeding, overtaking on turnings and hills, or enforcing priority, they will not be drunk with alcohol or drugged, they will not be tired or sleepy and will not get aggressive.

As a consequence of a significant drop in car accidents and collisions, the demand for tinsmith and paint services will fall dramatically. Most of the workshops will not be needed anymore. The proceeds from insurance premiums will also be significantly lower and thus the profits generated in this area by insurance companies. The influence of lawyers dealing with cases will also fall, although in Poland in contrast, especially to the USA, this segment of legal services is not well developed. The demand for medical and rehabilitation services for people injured in road accidents will also drop significantly, although in this case it will be a huge benefit for the whole society due to reduced pain and suffering and of course budgetary expenses (medical, emergency and police services). Doctors themselves, the remaining medical staff are so overloaded with work that the fall in the number of patients after accidents should be welcomed with relief, because thanks to that they will be able to better deal with other patients and their illnesses.

The demand for maintenance services provided by dealers will probably also decrease, because these cars will be operated in an optimal way, so their consumption will be lower and instead of repairs, they will be limited only to service inspections resulting from the mileage. It is also assumed that cars will be electric in the future, which means that the number of components and engine components and the transmission that can fail will drop significantly compared to cars with internal combustion engines, as well as the exhaust system which they simply do not have.

A revolutionary change will reach professional truck drivers, city buses and taxis, couriers etc. As the AV becomes popular, the demand for their services will decrease. There will be new jobs related to AV service and their control and coordination, there will also be new opportunities for programmers and IT specialists or accident investigation experts with the participation of AV. However, it should be remembered that the newcomers will be much less than those who will lose their jobs as drivers, which will certainly cause considerable social costs.

A huge question mark is the size of cars produced in the future. According to the author, the volume of production in the future will not change too much. The high level of use of autonomous cars, significantly exceeding the current $5 \%$ in the case of private passenger cars and high mileage will make these vehicles will have a much shorter life cycle and will significantly increase the frequency

17 Global status report on road safety 2015, World Health Organization, Geneva 2015. 
of their replacement. It will be beneficial that we will eliminate outdated, dangerous and high-emission vehicles from traffic.

In autonomous vehicles, solutions in the field of information technology become extremely important, so it is possible to decrease the importance of typical car manufacturers. The symptom of these changes is the fact that Google, Uber and Tesla have become pioneers of autonomy, of which only Tesla manufactures cars, and so it belongs to companies with very little potential, especially considering the production capacity. It may soon turn out that those car makers who do not make appropriate alliances and acquisitions or do not develop sufficient autonomy competences themselves will be marginalized.

\section{Conclusions}

The fact that autonomous vehicles will appear in the future on roads is basically a foregone conclusion. However, the direction in which their development will take place and whether they will free us from the deficiencies of today's transport systems without causing new problems is a matter entirely open and dependent mainly on experts, but first of all on politicians. Politicians must determine the appropriate regulations and, above all, determine the role and place of autonomous vehicles in transport systems and create such payment systems for their use and the services they offer which will shape this role and place properly. Finally, users should be assured that AVs are indeed much more secure than current cars, and that their privacy will not be compromised and that using AV will not end in permanent surveillance and professional drivers will find another job. The potential of autonomous vehicles is huge (first of all, reduction of energy consumption and emissions as well as labor costs, reduction of congestion and infrastructure space demand, as well as increased traffic safety), it should only be properly used and this seems to be the biggest challenge.

\section{References}

Ben-Joseph E., ReThinking a Lot. The Design and Culture of Parking, The MIT Press, Cambridge 2012.

Clewlow R.R., Mishra G.S., Disruptive Transportation: The Adoption, Utilization and Impacts of Ride-Hailing in the United States, Institute of Transportation Studies, University of California, Davis 2017.

Global status report on road safety 2015, World Health Organization, Geneva 2015.

Greenblatt J.B., Shaheen S., Automated Vehicles, On-Demand Mobility, and Environmental Impacts, Current Sustainable/Renewable Energy Reports 2015, 2, p. 74-81.

http://press.ihs.com/press-release/automotive/self-driving-cars-moving-industrys-driversseat (access: 9.03.2018).

https://www.fhwa.dot.gov/ohim/summary95/mv200.pdf (access: 9.03.2018).

Igliński H., Kongestia transportowa w Poznaniu $i$ wybrane sposoby jej ograniczenia, Transport Miejski i Regionalny 2009, 3, p. 1-8.

Igliński H., Babiak M., Analysis of the Potential of Autonomous Vehicles in Reducing the Emissions of Greenhouse Gases in Road Transport, Procedia Engineering 2017, 192, p. 353-358. 
Kröger F., Automated Driving in Its Social, Historical and Cultural Context [in:] Autonomous Driving. Technical, Legal and Social Aspects, eds. M. Maurer, J.Ch. Gerdes, B. Lenz, H. Winner, Springer Verlag, Berlin 2016, p. 42-56.

Norton P.D., Fighting Traffic. The Dawn of the Motor Age in the American City, The MIT Press, Cambridge 2008.

Paukert Ch., Audi says 2019 A8's Level 3 self-driving tech capable of doubling speed, https:// www.cnet.com/roadshow/news/audi-says-2019-a8-level-3-self-driving-tech-capabl e-of-doubling-speed/ (access: 9.03.2018).

Preparing a Nation for Autonomous Vehicles: Opportunities, Barriers and Policy Recommendations, ENO Center for Transportation, 2013.

Shoup D., Cruising for Parking, Access 2007, 30, p. 16-22.

Thompson C., New details about the fatal Tesla Autopilot crash reveal the driver's last minutes, http://www.businessinsider.com/details-about-the-fatal-tesla-autopilot-accident-release d-2017-6? IR =T (access: 9.03.2018).

\section{Corresponding author}

Hubert Igliński can be contacted at: hubert.iglinski@ue.poznan.pl 